\title{
Hidden variables to Covid 19: Zimbabwe
}

Mare Matthew- PhD Student systematic theology (UNISA), Master of Human Rights, Peace and Development (AU), Master of Religious Studies (UZ), Master Peace, Leadership and Conflict Resolution (ZOU), Master of Developmental Studies, Honours in Religious Studies (UZ), Part Time Honours in Political Science (UZ) and 12 Executive certificates in various fields. Mare is also National Aids Council, Board Member

Fortunate Chingono- BSC Honours in Sociology (UZ)

Spencer Mbazangi- MSC in Intelligence and Security (BUSE), BSC Honours in Intelligence and security (BUSE)

Simbarashe Mangezi- Hon in Political Science (UZ), Master of International Relations (Student-UZ)

Alexander Mare- BA Hon in Religious Studies (UZ), Master of Arts in Religious Studies

\begin{abstract}
This article analyses the contributing variables to the spread of the Novel Corona Virus Disease 2019 (COVID-19), in Africa and Zimbabwe in particular. Despite the fast-growing literature on Covid-19 and various propounded theories there is still little information specifically dealing with how each specific country in Africa was affected and the underlying contributing factors to the spread. Guided by findings drawn from both primary and secondary sources the study considered the upsurge in local transmissions in Zimbabwe as influenced by social, political, religious, and economic factors. These factors were narrowed down to detailed issues which include porous and weak boarder security, a dysfunctional transport system, corruption at both local and central government level, traditional cultural beliefs, myths, government's response and lockdown measures, stigmatization, poverty, social media, politics, weak infrastructure, and medical systems, refugee matters and the international or global perspective regarding Covid-19. Following the deep analysis of the various contributing elements the study recommended the need for increased disaster management awareness campaigns, constitutional education for the citizenry especially on citizen policing and change of the general attitude by the citizens toward pandemics which was observed as highly achievable by improving civil-security sector relations, and the empowerment of social, church, and traditional leaders to be more in charge of their areas of dominion. The study recommended ubuntu philosophy in disaster education, citizen policing to identify quarantine fugitives, community engagements, drawing lessons from the 1918 Spanish Flue responses, improved civil security relations, church leaders' involvement, community based organisations as agencies of change of perceptions, behaviours and attitude towards Covid 19. The study also recommended the need to utilize local knowledges.
\end{abstract}




\section{Introduction}

Pandemics of this nature and magnitude requires the new normal strategies as the bookish models are failing to address the pandemic in Zimbabwe. The government should adopt the whole of government approach with greater focus on community engagement strategies. The Local Agenda 21 clearly stated that nothing for the people without engaging the people themselves. Covid 19 policy and strategies are more of executive orders without the input of the affected people. This has resulted in resistance and politicization of such measures. The government should support community strategies through local government structures and community based organisation hereinafter CBOs doted around the country. People are wearing masks for the fear of police and the military and not for their own safety. This shows that, lockdown measures are yet to be understood from the health security perspective. The civil security relations, is also a key hidden variable in the management and mitigation of the Covid 19 health pandemic. Lesson can be drawn from 1918 Spanish Flue health pandemic where transport system enhanced the spread of the virus. Furthermore, urban to rural migration in

response to scaling down and lockdown measures is also a cause of concern. In 1918 urban rural migration aided the spread of then Spanish flue pandemic. And as if history is to repeat itself the first cases of both Spanish Flue and Covid 19 came from South Africa.

\section{Hidden variables to Covid 19 in Zimbabwe}

There are various nuances to the spread of Covid 19 in Zimbabwe which have not explored by both the government and researchers. Hidden variables refer to uncommon factors which are facilitating the spread of Covid 19 pandemic. This study is based on qualitative data gathering tools observation and interviews using a convenience sampling technique inorder to harness various societal perspectives and mind-maps. The disease is a novel hence more studies should be conducted inorder to guide future responses to this pandemic. Interms of hidden variables the study categorized various nuances into political, religious, economic and social spheres inorder to help to explain a surge in local transmissions and mortalities in Zimbabwe. Covid 19 response cannot be generalized because each and every country has its own unique factors which informs its response. Thus, every state is distinct in itself. The study, is focused on varied hidden variable that has led to the spread of Covid 19 pandemic more in urban areas than in the rural areas. 
Meanwhile, there are various responses and innovativeness as a result of Covid 19. Information technology became central to business operations and the virtual meetings are now the order of the day. In addition to that, people defied tradition where victims of the disaster would be domicile waiting for the government intervention to pro-active agents through various entrepreneurships. In most countries' citizens relied on government for relief but in Zimbabwe household interventions to include budgetary discipline, projects like raring of chickens amongst others. There is this nuanced thinking by Zimbabweans to disasters where victims of the disasters took proactive roles to mitigate the impact of the disasters. In each and every household people are consuming traditional herbs especially Zumbani teas, lemons, garlic, ginger and steaming as proactive measures to mitigate the impact of Covid 19. Whilst local infections are high the recoveries are equally shocking. Covid 19 is nolonger a threat as it is in the Western Hemisphere. WHO and the government of Zimbabwe should make scientific studies on the efficacy of local knowledges. Whilst these might cure the disease same are some of the measures which resulted in recoveries. With the health sector in Zimbabwe Covid 19 would have resulted in more fatalities. WHO had actually projected Covid 19 to have more devastating effects than in any other continent.

\section{Unexplained variables}

Covid 19 has brought with it the 'new normal' as it has brought with its non-traditional elements which researchers and scientists should explore. The society was shortchanged by Covid 19 and new elements being introduced into the society and affects how people relates. There are a number of yet to be explained variables for instance places which were supposedly feared to be Covid 19 hotspot turned out to be safe. There are places like Beitbridge, it is not only a transit route but also a hive of people entering and exiting the country by evasion. According to Diamon (2002:) Zimbabwe-South Africa border is tone of the most porous and fluid borderlands on the African continent and is the busiest road in Southern Africa. Thus, Beitbridge for example, due to its geo-strategic position is supposedly the Covid 19 hotspot because it is a major transit route in the Southern hemisphere. More, importantly South Africa has high infection rate. Instead Harare and Bulawayo are epicenters of Covid 19 in Zimbabwe and yet there are a plethora of security checks and major cities are not easily accessible. In addition to that, urban areas have higher awareness from both national response and selfawareness from internet and global news on various news channels. In rural areas through interaction one can note a serious knowledge gaps and what is evidenced is mere fear and 
resultantly they created self-buffers where visitors from urban areas are not welcome. There is evidence self-policing derived on local knowledges because the elders have vivid memory of the 1918 Spanish flu (NIH1 virus). The disease according to Arkira (2015:3) in 18 months 500 million people were affected and 50 million dead globally. During the colonial era the urban and rural areas were completely separated inorder to minimize the spread of Covid 19. The used of past experiences is one area that has not been explored. The hidden variable is the effective use of the oral tradition to respond to the present situation. The government todate, do not have a scientific explanation as to why the urban areas are worst affected than rural areas.

Various scientific studies linked Covid 19 to the immune system and with the level of food security in rural areas one would expect more fatalities in rural areas. When one considered the health system in Zimbabwe, rural areas are worst affected meaning to say they are more vulnerable to the pandemic. It is a fact that there is no known rural hospital or clinic with ventilators in Zimbabwe and yet underlying condition are both in rural and urban areas. The only variance of on organic food consumed in rural areas and genetically modified food stuffs majority of whom are both imported and smuggled from South Africa. In high density areas

like Mbare amongst others foodstuffs are remodified through repackaging in counterfeit containers and the only genuine element would be packaging. Thus, most people in high density suburbs are consuming substandard foodstuff which has serious ramification on their immune system. Dietary concerns are yet to be linked to health pandemics and high mortality rates in Zimbabwe. This can only be achieved through robust studies and universities are lagging behind in that respect. According to Rana (2019:1) organic foods keep the body by improving the immune system and help the body to fight diseases.

In rural areas, according to a United Nations report of 2020 derived from EU, FAO, USAID, OCHA and UNICEF combined reports of April 2020, they estimated hunger in Zimbabwe to be over 5.6 million people who are living in abject hunger and required urgent response (UN Zimbabwe Report:2020). Of the 5.6 million, 4.3 million are rural Zimbabweans including children. Additionally, the majority of these families are child headed. There is need to study the immune system of both urban and rural populace in relation to its natural response to diseases. There is a sense in which diet is a variable in disaster management. Globally, Covid 19 is synonymous to urban populace than rural and the same can be said of 1918 Spanish Flu. The biological makeup of the rural populace that eats organic food should be scientifically 
studied in relation to health pandemics considering the past health pandemics like the Spanish Flue, Ebola, HIV/AIDS and Covid 19. These are some of the hidden variables which must be explored by scholarships. And according to the New Global Food Crisis Report Forecast (GFCRF) on Zimbabwe projected that with millions of people already requiring humanitarian assistance due to prolonged drought, climate-related shocks, economic deterioration and the situation set to worsen as the Covid 19 pandemic spreads.

Rowe World Food Programme Country Director indicated the need to consider Covid 19 response and vulnerability as mutually exclusive variables and the government has been concentrating on Covid 19 negating food security (Rowe:2020). Thus, Zimbabwean situation is complex in that, there are plethora of factors which can be used to explain why the informal sector is ignoring lockdown measures and the high mortality rate. The existing food security vulnerabilities posed a serious threat resulting in the general populace defying the WHO guidelines because their humanitarian situation is a threat to their lives. Humanitarian considerations is weakening people's capacity to mitigate Covid 19. The other hidden variable is that the elderly is a neglected sector of the society in Zimbabwe with majority of whom already abandoned by their children. The demography of mental health cases in Zimbabwe are

the elderly due to traumatic disorder conditions. The majority had their children died of HIV/AIDS, road carnages amongst others and due to their exposure to various vulnerabilities like hunger they are succumbing to Covid 19 more than the young populace. These are some of the complex hidden variables that requires indepth study by both scholarship and policy makers. Zimbabwe's response to Covid 19 should consider these hidden variables to formulate a homegrown strategic blueprint.

\section{Sanctions}

According to a study carried out by Reliefweb on 22 April 2020, whilst USA and EU authorities say sanctions they imposed do not target aid, states and multilateral bodies must take concrete steps to ensure that sanctions do not hinder the response to the Covid 19 pandemic in countries already suffering humanitarian crisis (Norwegian Refugee Council News and Press Release: 2020). The UN Secretary General Antonio Guterres encouraged G-20 economic powers to waive sanctions to ensure access to food, essential health supplies and Covid 19 medical support. Zimbabwe is under sanctions since 2002 when ZIDERA was promulgated and EU restrictive measures. Since then, Zimbabwe's economy deteriorated and the government of 
Zimbabwe is failing to fulfil its UN R2P principle which is to protect, promote and enhance the rights and welfare of its citizens.

The health sector is poorly performing undermining its capacity to respond to Covid 19 effectively. As of August 2020, 300 frontline healthcare practitioners were affected and in some cases as a result of shortage of adequate and effective PPEs. In addition, there is acute shortage of ARVs and this is putting those with HIV/AIDS at a higher risk of succumbing to Covid 19. Meanwhile, there is no study so far done to ascertain the impact of sanctions to Covid 19 response in Zimbabwe. Without an adequate study on the impact of sanctions on disaster response, there won't be any basis for future UN considerations.

\section{The role of the community}

Police Act Chapter 11:10, Sub Section (3), empowers the Commissioner General of police to establish police constabulary to enhance community policing (Police Act Chapter 11:10, Sub Section (3)). Communities have various structures which can be utilized to manage and mitigate the spread of Covid 19 in Zimbabwe. The community has been very instrumental in exposing the escapees from the quarantine centres resulting in a sharp decline of case of individuals who escape quarantine centres. The communities worked together with the

communities to track and account for the fugitives. In the Zimbabwe Republic Policy's charter community policing is one of the key pillars in combating crime. This has seen the police establishing local structures inform of the neighborhood watch committees popularly referred to as 'ndini ndamubata'. The term 'ndini ndamubata' is a derogatory term by the community to try and discourage neighborhood watch committees by degrading them. These structures have not been fully utilized to respond to the Covid 19 pandemic. The neighborhood watch committees, if well utilized they would provide intelligence of the members of the communities who are covertly sneaked out the country through undesignated points of entry and exit. The government is failing to combat entry and exit by evasion and the majority of these individuals are couriers of the pandemic.

The government is yet to engage those communities who settled themselves on the no man's land and those communities which shared village borders. The communities adjacent to borders have intermarried and disregard borders. To the communities living at the borders view the physical border as fluid. According to Bolt (2016:17), undocumented migrants are occupying 
the no man's land to avert justice and relies on illicit border crimes. The scholar argues that the soldiers manning the borders they view them as merely border jumpers, transients fleeing Zimbabwe's crisis, with no claim on the border as a place of labour and the community is a source of cheap labour to Grootplaas farm hence their presence is virtually being legitimized by their attachment to the South African owned farms. In addition, these communities have established rapport with the soldiers manning the borders, they are their whistleblowers, conduits to coordinated corrupt and smuggling activities with these communities collecting safe passage fees on behalf of the securities and also source of free sexual pleasures. Thus, in the eyes of the security they are a 'necessary evil' but inlight of health pandemics like Covid 19, these illegal communities are now a health security. Apart from health security concerns the surge in number of these illegal settlements shall in the unforeseeable future create insurgence groups given South Africa's weak gun policy and the continued proliferation of small arms across Africa.

Apart from the illegal squatter settlements on no man's land the other challenge relates to historical settlements along border lines. These settlements views border demarcations as merely administrative lines and to them the border is fluid. When the countries closed boarders for each other due to Covid 19, communities illegally settled at porous border points continued to relate with each other. These communities have been there even during the colonial era the

lockdown measures could not stop these communities from relying on each other. The historical ties by these communities cannot be undone hence pose a serious threat to the spread of Covid 19. These communities move in and out of the country on daily basis to procure basic commodities, they have intermarried to an extent that the physical boarders have been diluted. When the government instituted its lockdown measures it made an oversight on these communities. These are some of the hidden variables to the understanding of Covid 19 response in Zimbabwe.

The value of community in Africa cannot be under estimated and the response to Covid 19 requires community considerations. Various societies have various traditions, beliefs and practices which bind and identify them. To note is that, some of the beliefs, traditions and practices are causing the spread of Covid 19. This study will identify some of the elements which are being overlooked by the government when responding to Covid 19. In every culture there are taboos and these taboos are an impediment to mitigating the spread of the Covid 19. 


\section{Clash of civilization between WHO guidelines and African culture}

There is a challenge of enforceability of the Covid 19 regulations especially on bereavement and burials. The WHO guidelines contradicted on how Africans manage bereavement resulting in violation of WHO guidelines. There is now a clash of civilization between WHO guidelines and the African culture. The majority of deaths in Zimbabwe are home situations because people now prefer to do homebased care and only informs the government after they finished rituals and incantations. The lack of reporting of Covid 19 cases is undermining government efforts to reduce mortalities resulting from Covid 19 infections. People nolonger trust the government with their Covid 19 relatives because the government is empowered by the law to limit their rights and tradition.

According to Stroebe et al (2001:6) mourning has psychological and physical manifestations and its manifestation is shaped by the practices of a given society or cultural group. Of concern to this paper is what is termed 'abnormal' grief usually involving central personalities within a family. According to Rhodes (2001) death is more than a biological act and has sociological and legal/political elements that influence any bereavement response. In addition, there are also spiritual and psychological elements (Hyse-Moore: 1996, Worden: 1991). Kaltman (2003:131) lack of management of bereavement result in cognitive disorganization, dysphoria, health deficits and disruptions in social and occupational functioning. Parkes (1972) noted that whilst

others may recover, there are antecedent, concurrent and subsequent factors which may impinge on the outcomes for the bereaved. The WHO guidelines on the burial of the Covid 19 victims is seemingly overlooking the concept of bereavement over the spread of the health pandemic. The post traumatic effects of such hashed decisions are equally problematic in the unforeseeable future. Provisions must be made to allow close relatives to mourn under the watch of either health practitioners, counsellors, psychologists and social workers.

Zimbabwe is a country with people of assorted cultural belief systems on handling and managing bereavement. However, there is a common trend on how Zimbabweans say, 'goodbye' to their deceased close relatives. It is pertinent to note that, some of the cultural elements are contributing to spread of Covid 19 pandemic forcing the government to suspend social gathering. The government instituted Covid 19 regulations based on evidence of lack of self-restraint resulting in the government instituting radical measures. Some of the findings relates to dead bodies being smuggled from South Africa through undesignated entry points 
and the majority of whom were confirmed and sudden deaths cases. Vice President Kembo Mohadi who leads the country's taskforce to tackle the pandemic, said smugglers operating along Zimbabwe's borders with South Africa and Mozambique pose a serious threat to efforts to contain the Covid 19 pandemic. The publication quoted Ms. Letwin Ndou of Tshingwanyani Village who fingered out soldiers and police as conduits to these smuggling activities. Mr. Muleya escorted the investigating journalists to cross to Mussina through Muruti farm where the security manning the gate open gates for smugglers (www.zimbabwevoice.com retrieved on 22 August 2020).

The study noted that the majority of the bodies being smuggled involved undocumented people who entered South Africa by evasion and on average most of whom had spent more than 20 years without even returning home. These timeframes are tempting close relatives to secretly convene and do body-viewing. The body-viewing is key in African culture in that, that is where close relatives confirming if they are about to bury the correct person, see the corpse for the last time, say few departing words to their deceased relatives and for the deceased to see the relatives for the last time. Without teaching people, the new norm people will perish in their numbers. Lessons can be drawn from first experiences of HIV/AIDS and on Cholera. On Cholera people would track bodies to rural area and they forcefully open and bath the dead bodies. In the aftermath, close relatives would die enmass. Thus, Zimbabwe must come up with its own model since the WHO guidelines are mere universal guidelines which did not consider minute cultural practices. There is need to domesticate the WHO guidelines by conducting selfunderstanding scientific researches.

The government of Zimbabwe adopted education 5.0 where the new thrust of the universities in Zimbabwe is to research and innovate. The universities should come up with various innovations to include provision of professional counselling and awareness programmes. Without proper guidance on bereavement relatives are continuously conducting secretive body viewing especially on Covid 19 victims who dies at home. The police and health officials are being called after close relatives have not only do body viewing but also conducted traditional practices bathing the corpse and incantations especially knowing that with the WHO guidelines health officials would not allow them to perform such cultural practices. The hidden variable is that, in Zimbabwe close relatives are delaying the government of sudden death cases to allow them to violate the WHO guidelines without external interference by the government. On 
Covid-19 death cases, how can one get closure without having said 'goodbye' to their beloved ones.

The double standards by the government, when a senior government official dies the restrictions are eased and more than 50 people congregates. The government must be mindful of the human nature and must avoid making assumptions that societies easily accepts the WHO directives when it is observing the government violating own principles. The government must lead by example, people observe National heroes and heroines being given befitting burials though under WHO guidelines and their relatives buried like paupers. There is need to balance the pandemic and the mental standing of all affected directly. Not having had the chance to grieve, the mental torture and anguish is overwhelming, and it pose another threat of post traumatic disorder. In 2029 then Minister of Health and Child Care made some shocking revelations that, in Zimbabwe out of a total of 14.5 million people a million have mental challenges.

The indigenous knowledge systems have mechanism of responding to bereavement. According to Sanni (2016:1) looking at most African countries, one realizes that the social imaginaries which make us we are, continue to be an issue in every society. In most if not all Zimbabwean rural societies handshakes are key gestures of consoling the beloved ones. In African societies the process of consoling is referred to as kubata maoko meaning handshakes. It is unsocial not to handshake the bereaved and as result funerals are now Covid 19 hotspots. The WHO

guidelines are resulting in many being labelled Westerners because through socialization handshakes became synonymous with consoling by Zimbabwe rural societies. Apart from handshake society monitors closely to ensure close relatives are seen crying resultantly, in most cases very close relatives end up falling on each other's legs and start to cry and with some fainting and people would rush to do medical aid to include mouth to mouth resuscitation. In rural society if you are women and a close relative, if you do not cry you are labelled a 'witch' hence the Shona adage, pafa munhu hapashaikwe muroyi mean in every death there is a witch. This has resulted in the concept of kunobvunzira meaning consulting the mediums and clinical reports do not have relevance in African culture. J.S Mbiti defined Africans as notoriously religious people and religion has permeated into their bloodstream (Mbiti: 1969:1).

In the moment of grief, a number of aspects are overlooked and pain eclipse the sense of judgement and reasoning. With the Covid 19 pandemic, communities must be well educated 
for them to understand that, handshakes and first aid transmits the disease. In the Zimbabwean society, if you are relatives and you don't cry enough to include fainting and falling on others you would be labelled a witch. Information dissemination helps to protect people from being labeled if they did not do the traditional 'kubata maoko' and demonstrate their pain. This is where mass media, CSOs, CBOs, NGOs comes in including engagement of traditional leadership to educate communities. The monies which are being spent on television and radios without known impact is more effective if it is to be channeled towards local structures and mechanisms.

In rural areas people are not buried like paupers, the body of a married person must rest for the night in the kitchen. If it is a woman who would have died issues of lobola and relationship with the in-laws is a key variable. In ATR the mother is not a relative as such upon passing on of the mother her close relatives take over burial arrangements and not the government. Meanwhile, close relatives bath the corpse and check to ensure that they are burying the correct person and to confirm if all the body parts are there. The concept of the living dead is equally important in the ATR, and the dead communicates anger through mumvuri meaning the shadow of the corpse. The mumvuri can only be observed when the corpse spent the night in the kitchen. The WHO regulations circumvent all these processes resulting in societies conducting secret burials. The idea of secret burials is to ensure that, tradition is followed.

Burial of a king, no king is buried like an ordinary person and neither is the illness, death and burial of the king announced. The Covid 19 regulations as guided by WHO guidelines do not conform with traditional practices and belief systems. The king is buried in a sacred place and without WHO guidelines or health official presence. These are some of the hidden variables to Coronavirus. Burial of a king who would have died of Covid 19 virus is a serious hurdle as there is a direct link between the burial of the king and the kingship itself. There are rituals to be followed if the kingship is to remain within the Chieftainship family lineage. Societies would do anything to ensure that, they protect power and kingship by violating WHO guidelines.

The new normal or new culture brought by Covid 19 should be understood from the perspective of the clash of civilization. The majority of the Covid 19 WHO regulates clash with the Zimbabwean culture. Where culture is under siege through drastic and conquest means there is bound to be resistance. The situation is further compounded by chiefs and spirit mediums who are relating Covid 19 to non-scientific explanations. While the government are giving 
scientific explanations and make statutory announcements the chiefs and spirit mediums are telling their subjects that the ancestors are angry and they need to be appeased. The societies are receiving contradictory messages. To add on church leaders are lying to their congregants that they have the power to protect their followers from Covid 19. The hidden variable is that the Covid 19 message is not harmonized and this is negatively impacting on the mitigation strategies by the government of Zimbabwe. Understanding of the hidden variables is very critical in crafting mitigation and preventive strategies.

\section{The impact of Covid 19 to educational sector}

Covid 19 created a serious disparity between the rural and urban areas, in rural areas children do not have access to e-learning platforms. In another sad development the majority the pupils in rural areas already married especially in Mashonaland Central. According to 2020 ZIMSEC statistics there are 650000 pupils nationally and only an average of 32000 elite learners in urban areas are enjoying exclusionary access to online learning. The majority of these rural pupils could not finish syllabus when the schools closed in March 2020. This has resulted in government critics labelling the current status quo an 'Apartheid' educational system where only the elite have access to benefit over others.

In Mashonaland central where traditional leaders interfaced by this research, in Rushinga have shown displeasure on rise in child marriages and in particular school children during this prolonged lockdown holiday. They bemoaned the government for not including children's programmes in its Covid 19 response programmes. The majority of these children have lost hope after schools were closed indefinitely. The government should have considered that, children are experiencing pandemic of this global pandemic for the first time hence the need to use participatory approach through what the scholar termed, 'communication for disaster response'. Child headed families are worst affected as the majority of whom have resorted to illegal gold panning where they are subjected to all sorts of ill societal behaviours. Girls are indulging in prostitution whilst boys being recruited into gangers known as 'vakomana vemabhemba'. The traditional leaders hinted that, having badly socialized these young girls and boys are not a menace who are moving around with weapons terrorizing communities and they bemoaned that, no school can now be able to tame them. The majority of these boys have since been arrested for various crimes against the state. The Covid 19 has not considered the children variable in its programing and response. 
There is likelihood of massive school drop ups after Covid 19. Whilst children in urban areas are having virtual lessons their counterparts in rural areas are not having same privileges and yet they are to be examined under similar conditions. The surge in data bundles, absence of network in some rural areas and unaffordability technical gadgets has affected the rural populace. The SADC, heads of state and government departments are engaging in virtual meetings through zoom and nothing much is being said about the educational sector especially primary and secondary education. There is seemingly lack of strategic foresight with focus being on the negative effects of Covid 19 than the opportunities and a more nuanced thinking resultantly. The government should have considered a paradigm shift from the old past. Meanwhile, the government has scraped and criminalized extra lessons and incentives for teachers and this is creating a hurdle for those parents willing to have their children undertake extra lessons for a fee. According to Mambo (2014) the government of Zimbabwe issued a statutory instrument banning extra lessons. Teachers for fear to lose their jobs are shunning private lessons resulting in the gap being filled by unemployed teachers and some graduates without knowledge in pedagogy. The government position on private lessons during the Covid 19 era remains unclear, with those engaging in virtual lessons doing so outside the policy framework.

The rural children are through circumstances set to fail and no study by educational psychologists has so far been made to inquire on the impact of closing schools for long period of time. In addition, these students especially those in the primary education are being told that the schools were closed because there is Covid 19 at school. Thus, parents were conveying Covid 19 messages based on their understanding of Covid 19 because the information on the statutory instrument used to close schools has not been communicated effectively. There are no programmes for the school going children on either print or electronic media. Now that children especially those in the primary schools were taught of social distance, sanitization and other WHO guidelines, in the post Covid 19 will these pupils accept to sit next to each other especially in rural areas where they sit in groups due to scarcity of resources. Forcing them to sit together, will these not create traumatic disorders and a hurdle to make them work in groups. These are some of the hidden variables to Covid 19.

Meanwhile, those in urban areas who are now used to virtual classes and have embraced the 'new normal', what is the impact of reverting them to old methods of learning. Should the 
government consider virtual learning as a form of learning in Zimbabwe. There is need to carry out a study inorder to ascertain the efficacy of virtual learning versus face to face learning.

There is also indirect variable to the educational sector that is the nexus between employment and the school where the child will go. Prior to Covid 19 pandemic the majority of parents were gainfully employed with some having their children's fees being paid for by their employers. With Covid 19 and the government directive for companies to downsize and that only critical staff being allowed to remain at work the majority of employed last their jobs. The majority of businesses were closed, declared losses and some being insolvent. With the majority losing their jobs those who relied on them were advertently and inadvertently affected. A number of students will be forced, to learn in rural areas or those schools which are lesser to those they were before Covid 19 pandemic. This drastic change will result in a second trauma and this will affect their performance. These are some of the hidden variables to Covid 19 pandemic in Zimbabwe.

\section{The importance of the psycho-social support to Covid 19 positive persons}

The importance of the psycho-social support has not been considered a serious variable to the spread of Covid 19. A number of ill health Covid 19 individuals deliberately infects other people hence the need to teach people to be restrain from being vindictive. This can only be

achieved through the provision of the psycho-social support. The distress and stigma that comes inherently with positive to Covid 19 usually results in post-traumatic disorders which if not managed manifests itself in such unethical behaviours like deliberate spreading of the Covid 19. The role of those who provide psycho-social support has not been clearly defined in Zimbabwe's Covid 19 response strategy. Zimbabwe must not entirely rely on other jurisdictions' Covid 19 response strategies but to come up with its own homegrown solutions to its own challenges which would considered, social, economic, religious and political considerations. In the recent past Zimbabwe has been sarcastically copy and paste South African government response strategies.

Zimbabwe had adopted devolution policy but the provision of psycho-social support mechanisms is yet to be decentralized to the family unit level. The bereavement and management of those living Covid 19 requires the services of social workers and psychologists. The indigenous knowledge systems are not sustainable as they violate the WHO guidelines on 
the management and mitigation of the Covid 19 pandemic. The abuse of alcohol in Zimbabwe is clearly an indication that, the majority of the Zimbabwean populace requires psycho-social support inorder to mitigate post traumatic disorders. Through globalisation and ITC people watch mass burials in Brazil, USA, Italy and South Africa hence the fear of the unknown has resulted in anti-social behaviours. It is alike people are waiting to die helplessly since people were told that there is no medication and those with underlying medical conditions are on high risk. Stress is now contributing to high rise in Covid 19 death cases in Zimbabwe.

There are a number of social workers and psychologists who are unemployed in Zimbabwe and the government should consider hiring them to offer counselling services to the bereaved families. The bereaved must undergo proper counselling and the government should not rush and forcefully implement policies. Death comes with shock especially when the death is impromptu given the nature of the pandemic. To some it takes time to kill and to others its sudden death especially when the person concerned has underlying medical conditions. Knowledge is power especially on health issues there is a serious Gap on information dissemination in our communities in Zimbabwe, what is mostly known by our members in the community are the lockdown measures not the Covid 19. Emphasis is more on enforcement of the lockdown measures and not awareness hence compliance is the greatest challenge in Zimbabwe. Through observation, the study noted that it is not easy to reverse a culture and value systems of the people especially when the pillars of that culture the spirit mediums have

a diverge perspective from the government position. The government of Zimbabwe underestimated the cultural dimension especially engaging the spirit mediums. Funeral gathering for example cannot be easily limited especially elements like handshakes. Without addressing the traditional leaderships there is bound to be serious schisms and the fight against Covid 19 would not be sustainable.

\section{The role of psycho-social support to Covid 19}

The importance of the psycho-social support has not been considered a serious variable to the spread of Covid 19. A number of ill health Covid 19 individuals deliberately infects other people hence the need to teach people to be restrain from being vindictive. This can only be achieved through the provision of the psycho-social support. The distress and stigma that comes inherently with positive to Covid 19 usually results in post-traumatic disorders which if not managed manifests itself in such unethical behaviours like deliberate spreading of the 
Covid 19. The role of those who provide psycho-social support has not been clearly defined in Zimbabwe's Covid 19 response strategy. Zimbabwe must not entirely rely on other jurisdictions' Covid 19 response strategies but to come up with its own homegrown solutions to its own challenges which would considered, social, economic, religious and political considerations. In the recent past Zimbabwe has been sarcastically copy and paste South African government response strategies.

Zimbabwe had adopted devolution policy but the provision of psycho-social support mechanisms is yet to be decentralized to the family unit level. The bereavement and management of those living Covid 19 requires the services of social workers and psychologists. The indigenous knowledge systems are not sustainable as they violate the WHO guidelines on the management and mitigation of the Covid 19 pandemic. The abuse of alcohol in Zimbabwe is clearly an indication that, the majority of the Zimbabwean populace requires psycho-social support inorder to mitigate post traumatic disorders. Through globalisation and ITC people watch mass burials in Brazil, USA, Italy and South Africa hence the fear of the unknown has resulted in anti-social behaviours. It is alike people are waiting to die helplessly since people were told that there is no medication and those with underlying medical conditions are on high risk. Stress is now contributing to high rise in Covid 19 death cases in Zimbabwe.

There are a number of social workers and psychologists who are unemployed in Zimbabwe and the government should consider hiring them to offer counselling services to the bereaved

families. The bereaved must undergo proper counselling and the government should not rush and forcefully implement policies. Death comes with shock especially when the death is impromptu given the nature of the pandemic. To some it takes time to kill and to others its sudden death especially when the person concerned has underlying medical conditions. Knowledge is power especially on health issues there is a serious Gap on information dissemination in our communities in Zimbabwe, what is mostly known by our members in the community are the lockdown measures not the Covid 19. Emphasis is more on enforcement of the lockdown measures and not awareness hence compliance is the greatest challenge in Zimbabwe. Through observation, the study noted that it is not easy to reverse a culture and value systems of the people especially when the pillars of that culture the spirit mediums have a diverge perspective from the government position. The government of Zimbabwe underestimated the cultural dimension especially engaging the spirit mediums. Funeral gathering for example cannot be easily limited especially elements like handshakes. Without 
addressing the traditional leaderships there is bound to be serious schisms and the fight against Covid 19 would not be sustainable.

\section{Hospitals turning away patients}

The hospitals are now focusing on Covid 19 and neglect other diseases and those with other conditions that requires dialysis and those with other underlying conditions being turned away. The hospitals are requesting Covid 19 test before treatment and admission of which other Covid 19 tests took upto 7 days before the results are out. The majority of people are dying enmass of other disease and yet the government's focus is now on Covid 19. Considering that since January to August 2020, only 104 fatalities were recorded and the majority of who are those with underlying conditions. The government must balance its response considering that, more people are dying of other diseases more than they are dying of Covid 19. There is no death that is more death than the other, hence the need to balance the response to Covid 19. A comparative analysis of those who died of Covid 19 visa viz those from other disease must be cross tabulated and the results would guide policy direction. The Covid 19 fatalities in Zimbabwe are less than those from other jurisdictions especially Europe.

In Zimbabwe nurses and doctors are in perpetual industrial action demanding PPEs and better wages. Resultantly, only critical conditions are being attended to with the rest being turned away. On Covid 19, only critical cases are being admitted due to shortage of ventilators and enough hospital infrastructure in the country. The nurses and doctors are raising safety issues

and conditions of service and the government has no capacity to meet some of their demands resulting in a 'go slow' or industrial action. The majority of hospital are operating with skeletal critical staff in line with Public Service Commission guidelines and this has limited the capacity of hospitals to respond to Covid 19 cases. The impasse between the government and the health sector has seen Covid 19 results for both Covid 19 suspects and suspected bodies' results taking longer than the anticipated to come out and during that period people would be spreading the disease. The ill health nature of Covid 19 virus makes people to be positive without themselves physically feeling it. In addition, in high malaria zone areas people are often confusing Covid 19 symptoms to that of malaria because they are the same. With some ending up dying with malaria due to late treatment resulting from first suspicion of Covid 19 who lab results took upto 7 working days and by the time Covid 19 results came out most cases of malaria would 
have been at the cerebral stage. Treatment of cerebral malaria in Zimbabwe is not effective due to the poor health delivery system.

In Zimbabwe, people are succumbing to Covid 19 and had their deaths being enhanced by obese, HIV/AIDS and one or more chronic comorbidities. There is a sense in which age, renal failure and comorbidities are Zimbabwe's strong risk factors for the spike in cases and deaths. Zimbabwe should ensure that, those with renal, HIV and aged have preferential treatment at both public and private hospitals. This can only be achieved if there is a scientific research and the results are used to inform policy direction. The research gap is one of the key factors contributing to government's failure to mitigate Covid 19 related deaths. Individuals with the identified strong risk factors should be strongly monitored and exempted from work or areas with higher exposure.

Zimbabwe has always been grappling to meet its SDGs and MDGs because a certain section of its populace who practice traditional medicine and are licensed under the Ministry of Health and Child Care. In addition to medical practitioners there are African Initiated Churches and Pentecostal church whose healing doctrine is premised on the claim that, there is no disease that Jesus cannot heal. Thus, they claim to have the healing powers over any disease and that Jesus manifests himself through the prophets. The two churches and traditionalists teach against hospitals and with the continued dilapidation of the hospitals in the country churches and traditionalists are overwhelmed with people seeking their help. In Zimbabwe, most people in rural are using traditional herbs to boost their immunities and the Covid 19 is concentrated in urban areas than rural areas. In urban areas most people do not believe or use traditional

medicine resulting in them relying on hospitals and the conditions and the capacity of Zimbabwe's hospitals is unsustainable. In urban areas, the majority of the populace is Christian and some of the Christian theologies regard traditional medicine as sin as God is the only healer through his prophets. The role of traditional medicine had been underscored when evaluating circumstances under which rural areas have less infections and more recoveries than urban areas.

The majority of people who would have recovered from Covid 19 are now in the habit of using social media platforms to record their self-testimonies and there is a growing belief in 'what works doctrine'. There is a surge in self-diagnosis and those who suspects themselves to be positive to Covid 19 nolonger visit hospitals to get tested but instead resorts to methods used 
by those who recovered. The most commonly used methods which have literally substituted the role of the hospitals includes amongst others, kunatira where one put a hot stone in water and cover self with a blanket inorder to steam oneself, concoction to include Zumbani tea, boiled ginger, lemon, garlic, lemon grass and added turmeric plus a teaspoon of vinegar four times a day, boiled guava and avocado leaves as water to drink, put onions and garlic in the socks when sleeping amongst other remedies. With the number of testimonies of people who recuperated after using traditional herb henceforth there is a drastic shift towards indigenous knowledge systems over formal health systems.

In Zimbabwe there are Covid 19 facts which are uncodified rules but the general practice currently underway. There is no hospital public/private that is admitting without a PCR Covid 19 results and each test is costing not less than USD 65 and the results delaying upto a week or two. There is no hospital that is admitting if one is Covid 19 positive and needing admission for other conditions. With the poorly performing economy, no healthcare professional will attend to a patient without PPEs. The poor who can't afford private medical care are finding it very difficult to visit formal hospitals where they cannot only afford but also being turned away, with only critical situations being attended to.

\section{Illness and inheritance}

Illness is one of the most important aspect in African societies given the secretive nature of the Africans. In most African societies people do not prepare inheritance will and is usually obtained verbally at death bed. At death bed that's where close relatives interact with their ill relatives for the purposes of being availed deep secrets. Hospital visits whilst they are done on

compassionate ground the inheritance component is the equally important. Resultantly, the deceased person's last words are considered the last testament and will. WHO guidelines do not permit Covid 19 patients to be visited even by the closest relatives. The materialistic nature of African societies is compelling most families not to declared sickness of their relatives showing signs and symptoms of being Covid 19 positive.

\section{Hospital Radios}

In the past hospitals used to have hospital radios and with the government's position on community radios, there is need to consider hospital radio broadcasting. These platforms would 
help to create synergies between the hospital and their communities interms of information dissemination. Public health information is best articulated through hospital community radio platforms. The same can be used to provide messages of hope during health pandemics. In Zimbabwe rural communities are lacking adequate information on the management of Covid 19 situations to include other health pandemics. The editorial and programing would be monitored to avert transmission of gloomy messages to patients like the death messages (Dr. Mushavi:2020). The hospital then flights the WhatsApp numbers and close relatives send greetings to loved ones admitted in hospital. The government of Zimbabwe should come up with own homegrown solutions emanating from identified challenges and hidden variable.

The CPU operations in Zimbabwe are highly centralized and has limited jurisdiction. The CPU is more inclined to natural disasters which are climate related like floods, cyclones. the mandate and the sphere of influence do not address health pandemics, road carnages amongst other emerging non-traditional threats. Disaster management in Zimbabwe has always been reactive than proactive one. The history of natural disaster reactions in Zimbabwe has always been the case of unsustainable reactionary measures. Disaster has three phases pre, during and post recovery stage and in Zimbabwe is only concentrated on the disaster phase, since most the state actions are reactionary than proactive. With this Covid 19 the CPU has been rendered ineffective and yet it is the only institution established through an Act of Parliament mandated to mitigate disasters in Zimbabwe. The reaction to Covid 19 in Zimbabwe is compartmentalized to Ministry of Health and yet the pandemic required the whole of the government approach'. When in other jurisdictions they are using the 'whole of the government approach', in Zimbabwe the Ministry of Health and Child Care is spearheading Covid 19 responses.

The use of too much propaganda and misinformation by the government is one area that that affected Zimbabwe adversely in the wake of Covid 19 pandemic. Since February 2020 when Covid 19 hit Asia and Europe and instead of making necessary arrangement the Ministry of Health and Child Care misinformed the nation and made false assurances that it was in control of the Covid 19 situations. It was after Zororo Makamba passed on as a result of failure to get a ventilator and socket plugs were malfunctional that frantic efforts were made and the question of preparedness came under spotlight. The idea of quarantine centres was an afterthought, only when SADC member states like South Africa and Botswana began to deport Zimbabwean 
nationals enmass. The security sector does not have effective quarantine mechanisms for both its members and top government officials.

The role of the security sector in disaster situations has not been clearly codified in Zimbabwe. There is more security sector reaction to acts or threats of civil disobedience than to disasters and health pandemics in Zimbabwe. The security apart from enforcing lockdown measures they must go further to conduct awareness campaigns to all parts of the country through, roadshows and loud speaker announcements through road and air. These are some of the hidden variables to the understanding of the Covid 19 situation in Zimbabwe.

The role of the village committees in Covid 19 mitigation and response is not clearly defined in Zimbabwe. Various voluntary village committee groupings are making frantic efforts to conduct awareness programmes. There are various village initiatives doted around the country. There is need to decentralize disasters in Zimbabwe to village level. In disaster situations information dissemination is very central and this lacking in Zimbabwe where traditional mechanisms like radio and television are used without evaluating on the efficient of these mediums of communication. The government of Zimbabwe underestimate the fact that, citizens have lost faith in radio and ZBC platforms due to over politicization of these entities.

\section{Civil security relations}

There is a high rise in cases where members of the public are defying and evading lockdown measures in Zimbabwe. There is no known study that had unearthed the underlying reasons on why there is resentment to Covid 19 regulations. The study inquired on the extent to which civil security relations in Zimbabwe is contributing to the spread of the pandemic. The relationship between the members of the security and the general populace is critical in crisis management. Since 1980 when Zimbabwe attained its independence the security and civilian

relationships has never been cordial and the Gukurahundi and the 2008 elections are some of the episodes which created a rift between the security and civilian populace in Zimbabwe. The civil-security relations is one hidden variable that has not been factored in, whilst responding to Covid 19 pandemic in Zimbabwe. There is a deliberate disregard of any security initiative as a result of the bad relations that exist between the security sector and the civilian populace. 
The security sector has the responsibility of enforcing Covid 19 regulations. The study found it very necessary to unpack the nature of the relationships between the security sector and the members of the civilian populace. This relationship has far reaching implications interms of the effectiveness of the enforcement by the security sector in Zimbabwe. Whilst every state is using its security services to enforce Covid 19 regulations, its effectiveness has not been explored on countries where there is existing bad security and civil relations. The citizens are openly defying the security services with some only putting on masks when approaching a security checkpoint. On the same time, there are no awareness programmes being conducted at security checkpoints. There must be two checkpoints first the awareness checkpoint and the security checkpoints simultaneously. Inorder to achieve, compliance the relationships between the citizens and those enforcing the lockdown measures is very critical.

Civil security relations, is also another cause of concern in Zimbabwe. The security is perceived as serving the interests of those in power than the interests of the citizens. Since colonial times in Southern Rhodesia the security sector has never been having vibrant civil security relations. In the Southern Rhodesia Chikurubi training depot was created for training of homeland security. In the post independent Zimbabwe, the support unit became the epicenter for quelling violent demonstrations. Pandemic enforcement is different from responding to riotous situation, for example patients are being turn away without being given the chance to explain themselves. Those without exemption letters are being detained and fined without looking into the merits of their circumstances. The hard law measures at roadblocks has created enmity between the general populace and those enforcing the Covid 19 regulations.

There is serious mistrust between the security sector and the civilian populace in Zimbabwe and Zimbabwe should have considered fronting chiefs and headman, leaders of political parties, church leaders, councilors and local CBOs. A snap survey has seen spirit mediums, chiefs, headman not wearing masks and interpreting Covid 19 as 'mhepo' meaning evil omen caused by angry ancestors. In other words, it is deemed a punishment from the gods and in

response they are conducting 'bira' meaning traditional gatherings in violation of the WHO guidelines that people should avoid to congregate. This disjuncture interms of those processes has serious ramifications on the spread of the Covid 19 pandemic in Zimbabwe. The state is assuming that it is on the same level of thinking with its citizens and yet there are serious disparities. 


\section{The invincibility of the security sector}

The invincibility of the security sector to Covid 19, to be considered a frontline staff does not mean one is immune to the pandemic. The security sector is being reckless to included bunching in vehicles without maintaining the social distance. In Africa the security is under siege if it lacks strategic foresight. They are abusing their state issued identities to smuggle people into streets. When returning home people nolonger want to provide them with transport resulting in them using ZUPCO public transport where they are further exposed to the pandemic. When verifying documents of the travelers they will get exposed and in their ferret teams there is exposure through socialization. The security sector while they are enforcing Covid 19 regulations they themselves requires to be educated. While enforcing the regulations they are using the power of legal knowledge and coercive power without themselves following the same regulations. The manner in which they bundle violators of the lockdown measures in their care without either observing social distance is one of the hidden variables to Covid 19.

Roadblocks and the public transport are some of the sources of infections, at roadblocks all passengers from the buses will be told to disembark and the area would be overcrowded as police vet letters on case by case basis. There is also stampede as people jostle to rush home before curfew time set by the government. Bus terminuses are some of the Covid 19 hotspots where the infection is being spread. Through observation there is no social distance when people stampede to board buses and when they will be getting back on the bus. Meanwhile, people checking on their letters, without water, soap, sanitizers and ablution facilities for the officers manning the roadblocks.

In addition, in Zimbabwe there must be a designated security apparatus trained to manage disasters. Disaster management requires a specialized training on how to deal with the traumatized citizens in a pandemic situation. The concept of homeland security which is there to deal with various threats of traditional and non-traditional nature like riots, floods, cyclones, health pandemics like Covid 19, cholera, Ebola amongst others. Zimbabwe do not have a

vibrant disaster management strategy to include early warning systems. the history of disaster management in Zimbabwe is the history of reactionary than pro-active strategies. Taking lessons from the past, the CBOs were the umbilical code with the Manicaland community during the Cyclone Idai pandemic. Through these structures will the government be able to reach out to the communities effectively. The government must recognize CBOs as essential 
service providers who requires funding to conduct door to door awareness programmes in rural areas. Those with underlying medical conditions and the aged being the most vulnerable groups who requires technical and awareness advice. The issue of key populations in rural areas is being overlooked.

\section{Politics and Covid 19}

Globally, the Covid 19 pandemic was highly politicized with over 2000 conspiracy theories. China and USA used Covid 19 as a political strategy to further the existing turf based on trade war. Zimbabwe has a number of conspiracy theories and these theories have an effect on how the society respond to the Covid 19 pandemic. Former Health Minister Madzore argued that, we can't manage Covid 19 epidemic through brutality and he called for what he termed demilitarization of the fight against Covid 19 pandemic. He went further to describe the duskto-dawn curfew imposed by the government as a political strategy to curb anticipated protests over alleged grand corruption by some government officials, the economic and humanitarian crisis and the deteriorating democratic space. The Johannesburg Society of Advocates accused ZANU PF 's First Secretary for rising abuse under the guise of Covid 19 lockdown. The panel accused President Mnangagwa of abusing Covid 19 to arbitrarily arrest his political opponents. The ANC's International Relational Committee chairperson Lindiwe Zulu said there is urgent need to resolve the political crisis in Zimbabwe.

The role of national security intelligence is increasingly difficult as developed states are under new security pressures in a complex and uncertain international environment. Currently, leaders and decision makers in many states are struggling to find answers to the challenges which now face them. The intelligence services should have conducted strategic intelligence analysis of Covid 19 pandemic. Thomas Quiggin (2007) in Seeing the Invisible predicted the possibility of a pandemic caused by the $\mathrm{H} 5 \mathrm{~N} 1$ virus which is a precursor of a future pandemic that are somehow being overlooked despite the near global focus and the billions of dollars being spent. Quiggin call it faint signals and early warning signs of future pandemics. Considering political polarization in the country the intelligence services should have foresaw

the use of conspiracy theories to discredit Zimbabwe. When the USA declared Zimbabwe its key enemy, Zimbabwe should have foreseen, the use of American approach to discredit nations. The same tool which was used on China and other aggressors of the USA government. According to Jervis (1976:32) strategic intelligence assessment is to provide actionable 
knowledge or anticipatory warning to decision makers. The role of strategic intelligence foresight to Covid 19 pandemic is one of the hidden variables that is being overlooked. If Covid 19 politics is not well managed the conspiracy theories are going to effect regime change agenda. The term 'Covid 19 politics' is a term proposed by this study to refer to the new political culture where disasters and pandemics are now a new political tool. South Africa for example is now propagating low level xenophobic attacks were foreigners are being targeted for deportment. The same applies to Botswana amongst others.

Internally, there is Covid 19 politics brewing and a new political culture is brewing. The ' $k u d i r a$ jecha musadza' meaning putting sand in Sadza is a new political culture in Zimbabwe where political conflict resolution mechanism now includes making the government ungovernable through sabotage. Through the 'kudira jecha musadza' concept all efforts by the government to respond to Covid 19 pandemic is in limbo and effort by the government is being diverted towards managing public relations. In Zimbabwe the general citizenry has developed a tendency of just opposing any government programme. According to Kahuni The Herald correspondent on 22 December 2018 stated that, pouring sand in the dish is a self-defeating political strategy. The concept was highly popularized political strategy synonymous with the MDC Alliance. Kahuni argued that judira jecha musadza political strategy is a furtherance of ZIDERA and both are aimed destroying the economy (The Herald: 22 December 2018). There is serious political polarization in the country and the opposition is geared to oppose anything from the ZANU PF led government. Covid 19 is one of the highly politicized discourses in Zimbabwe and it has lost its humanitarian nature. This is unlike world over where the pandemic is viewed purely humanitarian and a health security matter. Studies must be done to ascertain the extent to which the judira jecha musadza political strategy is affecting the government's effort to mitigate Covid 19 pandemic.

There is also 'politics of employment' where companies are taking advantage of the Covid 19 pandemic to arbitrary abrogate the labour laws. The violation of labour laws also contravene International Labour Laws on the condition of services of all employees. There is misconception of what it meant to say, lockdown and skeletal staff. The majority of the

companies took it to means arbitrary violation of workers contracts with permanent employees being put on part time, contracts. These employees lost their key sources of sustainable livelihoods as a result of the government's proclamation of lockdown and skeleton stuff. Those who were on part time jobs lost their jobs without any option for compensation or being rehired. 
Resultantly, there are more traumatic disorders as a result of the government policy posture than the threat of Covid 19 itself. With the banning of churches and any social gatherings the counselling and clinical psychologist gap has not been addressed. Resulting, suicidal cases, domestic violence, divorce, house burglary, smuggling is on the rise as citizens are geared to do 'anything and everything' for them to survive. Those few individuals who are still gainfully employed are now 'soft targets' for thieves and burglaries. On the other hand, police investigations on death cases, has pathetically deteriorated against Article 2 of the European Convention on Human Rights and also in line with Minnesota protocol on effective investigations.

Due to over politicization of the Covid 19 pandemic, through observation one can tell that, there is evidence of misconception of the lockdown measures especially in high density suburbs of Zimbabwe. The majority of people are abusing their stay at home by engaging in nefarious activities. Most people are spending time drinking opaque beer, children playing in groups since the schools are closed, communities watching soccer and betting to raise income, praying and in informal trading without even observing the social distance or putting on the PPEs. In most communities both urban and rural lockdown measures are seen a punishment and a direct threat to their livelihoods. Shops are closing business at 1500 hours but operating backdoor and the same applies to liquor shops. Houses are being turned into distribution centres with even security officers being observed buying from these illegal outlets during the wee hours. The WhatsApp platforms are being used for coordination by regular customers.

\section{Entry by evasion at border posts}

There is rise in case involving entry by evasion across all the borders in Zimbabwe. At borders like Nyamapanda, Forbes, Kazungula, Plumtree and Mukumbura people are using undesignated entry points to smuggle good for commercial considerations. Whilst across the country they interact and possibly contaminate Covid 19 and since they do not use passports the government consider them as local cases with no history of travel because they check for official records to arrive at such a conclusion. The majority of what are alleged to be local cases are not local cases they are foreign cases by individuals who are not only formally recorded.

This impacts on the Government's strategic response to Covid 19. The entry by evasion variable has not been considered. This shows that citizens are trivializing the impact of Covid 
19 by emphasizing more on economic gains over health security concerns. Through deductive reasoning Covid 19 education remains inadequate.

The concern is primarily on Beitbridge where dead bodies, positive cases are being smuggled into the country through undesignated entry points. There are push factors to be considered which is contributing to the people opting to resort to entry by evasion. These factors include amongst others, the majority of Zimbabweans in South Africa entered the country through evasion and are undocumented and upon death the funeral parlors remove bodies of those with papers, those without papers are buried like paupers and Zimbabweans in South Africa would be observing, it is now expensive to repatriate a body from South Africa due to lockdown at embassies and consulate offices with Pretoria having closed, the segregation that is associated with being positive to Covid 19, people fear to associate with known positive cases due to contact tracing which result in all close associates being quarantined and being quarantined meaning limited from fending for the family, the new regulation for repatriation is that only the body and the parlor driver are allowed to cross the border meaning children, wives, husbands are nolonger able to bury their loved ones and with these factors people are resorting to smuggling because it is the only avenue left.

Inorder to avoid government scrutiny relatives conceal information particularly of those who entered the country by evasion after having tested positive and opt to return back home secretively. The majority of the diasporian community have witnessed the bureaucracies and expenses involved in repatriating dead bodies and those who contaminate Covid 19 opt to return home and waiting for the fate of life. Without close relatives, it is difficult to manage self-isolation alone and in a foreign country where foreigners are discriminated against. With the rise in xenophobic akin to apartheid being in a foreign country without good health is precarious. The government of investigate the causes of entry by evasion and why the sick is being smuggled back into the country.

\section{Attitude of the citizenry towards the security sector}

Whilst the security sector liberated Zimbabweans from the colonial bondage the post independent civil military relations has not been cordial. Interms of the civil military relations the security sector is supposedly the servants of the citizens but in Zimbabwe the opposite is 
true. There has always been running battles between the citizens and the members of the security sector since 1980 todate. The negative perception on the military as oppressors negatively impacts on the mitigation of the Covid 19. Perception is a critical variable when managing disasters or pandemics like the Covid 19. The community has devised codes to alert each other of the arrival of the security sector tasked to implement Covid 19 regulations, and people would scatter in different directions. There is lack of self-introspection on the part of the general citizenry with regard to Covid 19. There is need for people to understand that, with or without law enforcement there is need for self-policing. People ought to understand that, they have the legal obligation to protect themselves and to comply with the laws in the country.

The lockdown measures in Zimbabwe are lopsided in that, emphasis is more on barring people from getting into towns as if to suggest that Covid 19 is in the Central Business District. This has given a very wrong impression of the Covid 19 in Zimbabwe resulting in people especially in rural and high-density suburbs failing to observe WHO guidelines. A snap survey in the rural and high-density areas is that, Covid 19 is urban and that in high density areas the government is punishing us for voting opposition. In Kuwadzana 4 yet to be identified women had to source black magic in form of bees to prevent the enforcement of the lockdown measures. The other challenge is that, lockdown measures have lost tract considering high corruption rate by those enforcing these regulations, instead of arresting they are demanding bribe. The term 'catch and release' has been coined to try and expose the sophistry of corruption in Zimbabwe.

The concept of running battles between the law enforcement agents especially police and municipal police versus vendors. It is now common that, there is always running battles with civilian populace. In this context when Covid 19 came there was high polarization and the fear for law enforcement agents is nolonger there especially police and municipal police. The only entity feared by the populace is the military and with the November 2019 episode the members of the civilian populace now expects the military to be on their side whilst gang up against the state. There is misconstrued civil military relations in Zimbabwe. The civilian because of their perception that, military is on our side they have devised method of neutralize them through coordinated bribes. Citizens are now buying the loyalty of the military through bribes making enforcement of the lockdown measures difficult to implement. This is now very prevalent at boarders and at roadblocks. The government must consider a united states dollar cushioning allowances for those who are enforcing the lockdown measures because those found violating lockdown measures are dangling hard currency in exchange of their freedom. With the salaries 
below poverty datum line resisting hard currency becomes inevitable. This is further compounded by the fact that; senior government officials are allegedly engaging in disaster profiteering through nefarious corrupt activities like the Drax scandal. Disaster profiteering is a new political culture that impedes disaster responses in Zimbabwe. Disasters now presents opportunities for making money hence the sincerity of mitigating the pandemic is now secondary and survival first. Disaster deployments are viewed from monetary perspective more than humanitarian.

\section{Urban versus rural spread of the pandemic}

In Zimbabwe and many other African states, Covid 19 is more prevalent and has many deaths in urban areas than in rural areas. Interms of awareness and access to a plethora of awareness programmes urban areas have more access than rural areas in Zimbabwe. In Zimbabwe most of its rural areas are inaccessible and remote. In Zimbabwe disease such as HIV/AIDS, Malaria has more devastating effects in urban than rural, but Covid 19 seems to have presented a new dimension. Studies must be carried out to unpack the hidden variable relating to spread and scope of Covid 19 in urban areas and rural areas. The same trend has been noted in 1918 when Zimbabwe was affected by the Spanish Flue. In addition to the concept of urban infections, high density suburbs are affected more than low density suburbs. If this point is valid, urban planning has an impact to the spread of health pandemics, if one is to consider cholera, Covid 19 and the Spanish Flue.

There is scholarly gap to Covid 19, a number of studies, hypothesis and models for Zimbabwe must be carried out. Todate, there is no explanation on why Harare has less recoveries, more fatalities than other provinces. What is it that people in Harare are not doing that is being done in other provinces. There is also a pedestrian view point that, Harare's fatalities are as a result of referrals of patients to central hospitals and key private hospitals like Baines, Avenues, Rock-Foundation, Beatrice Infectious Centre, 24 Hour, Dandaro amongst others. Interms of referral hospitals, Parirenyatwa and Harare hospitals are key referral hospitals. Resultantly, all serious cases are being referred to Harare. The scholarships should be able to explain these hidden variables systematically. 


\section{Information, Communication and Technology (ICT)}

ICT has presented both the opportunity to link the world in a global village and also an opportunity for the weaponization of ICT to undermine human and state security. Zimbabwe was hard hit by a wave of media propaganda, exposure of corruption, self-testing methods and non-medical responses, counterfeit exemption letters, coordination to circumvent lockdown regulations like beer and church gatherings amongst others. The ICT especially, WhatsApp group platforms have been abused especially by those selling beverages at home and beerhalls secretly against the lockdown regulations. Same is being used to coordinate border crimes like smuggling of dead bodies and trafficking of the people to enter and exit the country by evasion. These are some of the key elements that have undermined Covid 19 response hence the need to study the extent to which the ICT variable is contributing to the spread of Covid 19 in Zimbabwe.

The ICT is another hidden variable to Covid 19 in Zimbabwe, the Ministry of ICT should consider zoom platforms to link the families with their patients in hospitals. The patients in hospitals are distressed, no visits from the family and the post traumatic disorders are not being considered for the Covid 19 patients and their immediate families. The occurrence of the Covid 19 do not remove the family bond. The zoom platform would enable families, church leaders to interact and pray for their relatives in hospitals virtually. In Africa most people do not plan for their deaths, they only do that on their death beds and communication with the sick relatives is considered an essential element. Most secrets are revealed at deathbed and hence the need to put in place ITC platforms in hospitals to mitigate the traumatic disorders associated with nonvisits to Covid 19 patients. The majority of Covid 19 deaths in Zimbabwe are post humous or death of arrival as relatives are concealing information from the government because of the bureaucratic challenges associated with having one's relative admitted. These are some of the hidden variable to increased number of local transmissions. Health officials directly in contact with Covid 19 patients should be key informant interviewees because they have direct access to the concerns of the Covid 19 patients.

\section{Self-Isolation and Quarantine}

Self-isolation and quarantine measures are some of the commonly adopted measures to suspected and confirmed cases. However, the applicability of such measures to developing countries is yet to be ascertained considering that, in high density population upto 6 or 8 people 
live in a single room. The socio-economic conditions made it impossible to do effective selfisolation and quarantine. In addition, it remained to be seen on whether children have been

effectively educated about self-isolation and quarantine given that majority of families in Zimbabwe are child headed families due to various circumstances. Those with children under the age of five whose parents are positive can they be able to observe social distancing and other WHO guidelines. The Covid 19 response requires a whole of government approach where various interventions are directed by the central government. The universities should conduct various researches and come up with various strategies and interventions.

Zimbabwe is faced with resource constraints and those who test positive are told to recover at home. The majority of the Zimbabwean population are low income earners who live in the high-density suburbs. In one room an average of 5 to 8 people lives in a single room due to the socio-economic hardships. Self-isolation being propagated by WHO is a concept of developed countries where a majority population lives in low density suburbs and majority of whom are multiple house owners. The hidden variable is linking poverty to the spread of the health pandemic.

What does total lockdown mean to a country with 85 percent of its population unemployed and is living in high density suburbs. The majority of this unemployed population are degreed and as such they spent much of their time debating national issues on social media platforms especially WhatsApp and Twitter. The most topical issues being the government of Zimbabwe's failure to have vibrant health institutions, corruption of Covid 19 resources, neglecting of domestic health systems by senior government officials who in the past sought medical assistance abroad, Covid 19 as an equalizer between the rich and the poor, stigmatization of senior government officials who test positive or die of Covid 19 pandemic, pandemic responses especially lockdown measures as political tool to suppress opposing elements, that Covid 19 is for the elite, that it affects those with underlying conditions, confessions by those who recovered from the health pandemic, naming of ridiculing of senior government and party officials who contracted Covid 19, publishing unofficial Covid statistics, exposing of corrupt tendencies through investigative journalism and Hopewell Chin'ono is one of the investigative journalists who exposed the Drax scandal which sucked in the Minister of Health and Child Care, Obadiah Moyo, Nat Pham pharmaceutical, PRAZ, Delish Nguwaya amongst others. The social media has contributed to the lack of confidence between the citizens 
and the government of Zimbabwe. This has serious ramification towards Covid 19 mitigation strategies and there is nolonger citizen confidence. Instead the citizens are now agitating for

the removal of the government. Social media should be considered as a hidden variable to the study of Covid 19 in Zimbabwe.

\section{The role of corruption to Covid 19}

Corruption is one such an area that has not been explored in relation to the spread of Covid 19 in Zimbabwe. The corruption relates to Covid 19 resources which are being abused at bureaucratic level. Corruption in Zimbabwe is so cancerous that it has affected enforcement of the Covid 19 regulations. The security agents who have been tasked by the Government of Zimbabwe has some its members involved in corrupt activities. The night raids are not yielding much impact because they are marred with a lot of corrupt tendencies. The most critical form of corruption relates to border security where there is entry and exit through evasion. Whilst physical boarder security is a challenge, entry by evasion remains a security concern inlight of the Covid 19 pandemic.

There is also a syndicate of people who are making counterfeit letters and sell them for USD 50 to non-essential services. On the other hand, people are corruptly manufacturing fake letters to pretend as if they are essential services. These counterfeit letters are also contributing to the spread of Covid 19 in that, people end up congregating in town without plausible reason to be there. The ICT and unemployment had resulted in many Zimbabwean perfecting corruption and white-collar crimes are on the rise. The situation was further compounded by the presence of such tribes as Nigerians in Zimbabwe. This is not to say, Nigerians are to blame for corruption in Zimbabwe but they brought with them some sophistry in white collar crimes. The ICT is both a blessing and a curse in Zimbabwe especially in relation to counterfeit.

The corruption at the borders coupled with the porosity of the physical boarders itself is a cause of concern. There are a number of allegations that, the Malaichas are smuggling dead bodies through undesignated entry points. The smuggling of dead bodies from South Africa covered with groceries is a cause of concern given that the majority of these bodies are those of suspected Covid 19 positive cases. In addition to these dead bodies covered with groceries to be consumed by recipients, people are also be trafficked through those undesignated entry points. To add on there are rampant cases of corruption also involving security apparatus who 
are bribed to turn a blind eye to these heinous acts. The contribution of corruption, porous borders, the touts who turned into smugglers is yet to be systematically factored into the study

of Covid 19 in Zimbabwe. The concept of surge in local transmissions should be understood in this perspective.

\section{Promiscuous}

The other hidden variable is that, there are a number of live in during the lockdown period. Students at various universities, unmarried man, secret parties, promiscuous is on the rise, 'small houses', prostitution is on the rise. This is the same challenge that can be used to explain the rise of Corona virus cases in South Africa. The irresponsible sexual contact is the other variable causing the rise in local transmissions. There is no education being done to educate the publics on the dangers of promiscuous on the spread of Covid 19 pandemic. Sex defies social distance as prescribed by the WHO guidelines hence the need to encourage responsible sex and faithfulness by sticking to one partner. The citizens are using their lockdown time irresponsibly. There is need to investigate and inquire on the nature, character and the behaviour of the Zimbabwean citizens. Behaviour is influenced by culture, education, socialization, exposure, attitude amongst other variables. This is to say, Zimbabwe should come up with own model and a scientific study of its own citizens. In the long term, Zimbabwe should consider studies in anthropology inorder to fully understand its citizenry. The situation currently obtaining in the country is indicative of the failure by the Government of Zimbabwe to understand its own citizens. Zimbabwe has various tribes and each tribe has its own culture, tradition and practices which must be considered when responding to pandemics and disasters like the Covid 19.

\section{Conclusion and Recommendations.}

Apart from the WHO guidelines on Covid 19 response the government of Zimbabwe did not go further to conduct a study to inform its response based on its own conditions. The study further concluded that, the government should open up to research inorder to help the government in its response to Covid 19 and coming up with own models and theories applicable to the Zimbabwean situation. 
The study recommends the adoption of the 'whole of the government approach theory' to disaster management in Zimbabwe. The whole system of government must work together using various skills to respond to global pandemics like the Covid 19. The CPU for example has demonstrated its limited capacity to deal with viral health pandemics hence the need for a whole of the government approach.

The study recommends the adoption of the term, 'disaster profiteering theory' instead of the term 'corruption'. The study considered corruption as one of the methods of disaster profiteering and not an end in itself. Considering the past management of disasters in Zimbabwe, whilst disasters and pandemics are a threat to human lives some views them as opportunity for making money. This new culture to disaster management in Zimbabwe has resulted in the promulgation of a theory of disaster profiteering where corruption is one of the methods. There are other methods like looting and diverting donated resources, theft of funds, abuse of office, pricing regime, allowances amongst others.

Disaster depoliticization theory has been mooted by this research to describe the abuse of disasters for political expedience. The disasters in Africa are a tool to silence the government critics. The majority of politically motivated laws and policies are crafted during extra ordinary situations and disasters and pandemics are one of them. The overpoliticization of disasters is a cause of concern to disaster and pandemic response in Zimbabwe. There is also abuse of the human rights discourse by opposition political parties in as much there are also underhand responses to disaster situations. There is more emphasis on politicking over humanitarian concerns to disasters in Zimbabwe. The courts are clogged with cases where citizens and organisations are challenging government measures to respond to global and national pandemics. The cause of concern is the mischief rule where the objective is more political than humanitarian considerations.

Human security and disaster management theory, this theory has been motivated by some of the security sector personnel allegedly engaging in nefarious corrupt tendencies whilst enforcing Covid 19 regulations. The human insecurity considerations result in the acceptance of bribes for safe passage by violators of Covid 19 regulations. Those enforcing disaster regulation should be well remunerated to avert the temptation of accepting bribes to meet own human insecurities. The study noted that there is a direct correlation between human insecurities and disaster management in developing countries where salaries are way below the poverty datum line. 
The study also recommends the adoption of the early warning health security theory, this theory was informed by the national and global security threats posed by health pandemics. The 1918 Spanish Flu, Ebola pandemic and the Covid 19 is evidenced enough to promulgate the early

warning health security theory where the security sector globally should consider health as a national security threat. The health pandemics have proved to have same weight to known global wars like the WW1 and WW11. Resultantly, states should consider early warning measures to mitigate the impact and effects of health pandemics to state security. No doubt, relations amongst states have been adversely affected by the effects of Covid 19 pandemic. 


\section{References}

Akira H. (2015), The influenza pandemic in Japan 1918-20. Aries, P. (1983) The hour of death, Oxford, Oxford press

Bolt M. (2016) Zimbabwe's migrants and South Africa's border farms: The roots of impermanence, University of Birmingham

Bowman, T. (2000) Bereavement and shattered dreams: Exploring the connections, Bereavement care.

Daimon A. (2002), Smuggling through fluid and porous African borderland and the state's responses: The case of the Zimbabwe-South Africa border, University of Zimbabwe.

Kaltman, S. \& Bomano, G. A. (2003) Trauma and bereavement: Examining the impact of sudden and violent deaths.

Mambo, E. (editor) (2014) The Independent newspaper

Mbiti, J.S. (1969) Religion: A new struggle for African Identity, Stellenbosch University Norwegian Refugee Council News and Press Release of 2020

Police Act Chapter 11:10, Sub Section (3)

Rana, A. (2019), How is organic food better for your health. Also found on https://medium.com/@ajayolinecake/how-is-organic-food-better-for-your-health$946 \mathrm{e} 9 \mathrm{~b} 33 \mathrm{e} 346$

United Nations report of 2020

Jervis, R. (1976), Perception and misrepresentation in international politics, Princeton University Press

Quiggin, T. (2007), Seeing the Invisible: National security intelligence in an uncertain age, World scientific press. 